\title{
The Educational Game “Indonesian Tribes” for the Kindergarten Students
}

\author{
Pikir Wisnu Wijayanto ${ }^{1}$, Yahdi Siradj ${ }^{1}$ \\ ${ }^{1}$ School of Applied Science, Telkom University, Indonesia \\ Corresponding email: pikirwisnu@tass.telkomuniversity.ac.id
}

\begin{abstract}
This study describes the educational game "The Indonesian Tribes" as multimedia application to facilitate the learning activities for the students in kindergarten. This multimedia application is designed to help the students to recognize the several tribes and cultures in Indonesia such as the traditional clothes, houses, dances, and the gamelan musical instruments. This application is equipped with a Kinect sensor technology to detect the external trigger such as speech and gesture (motion) recognition that will encourage the students' enthusiasm in playing and learning activities. It is in line with their characteristics who love to play and learn with their own imagination. This game education is also completed with audiovisual animations in various contents, and interactive nature with a simple English descriptions and instructions.
\end{abstract}

Keywords: educational game, Kinect sensor technology, "the Indonesian Tribes" game. 


\section{INTRODUCTION}

The use of a multimedia application in teaching learning activities for young learners is developing rapidly and being followed by the implementation of electronic games which become more entertaining and enjoyable. Among all the kinds of games, there is a specific category that is called an educational game, which has one objective beyond just entertainment, and that is education. This is because of the fact that educational game is applicable with the characteristics of the young learners especially for kindergarten students who like to play and learn, as well as their imagination. As stated by Adams (1973) that an educational game is a form of a game that is designed to demonstrate people about a specific subject and to provide a skill of educational or learning experiences including types of traditional games and "modern" in which was given charge of education and teaching. The tool of an educational game brings the psychological need and benefits in the learning process and it has become main-stream for educators, governments, and parents. Marsh, et al. (2005) and Aldrich (2006) stated that the educational game can support the learning process of education. By implementing the educational game in learning process, a student has an opportunity to try out and adjust much of what they see and hear; the game is, therefore, a source of cognition for them.

According to Aldrich (2006), one of the significant advantages of an educational game is the facility of animation that can improve memory for young learners, so that they can keep learning the material in a longer time compared to conventional learning. An educational game, therefore, can enhance the way of kindergarten students to understand the essence of learning through play. It allows them to better functioning of some sensory they owned, such as the senses of sight, hearing, and motorist functions. Through the interactive content, the roles of a multimedia application can also increase the teachers' creativity in teaching, and it will become more interactive, effective, and create a good atmosphere in the classroom. As stated by Siradj, et al. (2014) that educational game with multimedia-based interactive contents can be designed for the students to visualize easily to the problems that seem complex or complicated in the real world. It is expected that the students can learn various essence in real events with pleasurable. Therefore, the students always feel fun and enjoy in following the teaching and learning activities. To acquire the language skill or proficiency in the learning process, the kindergarten students need not only to keep repeating the desired part of a target language but also to be enjoyable every time. This is due to a fact that the kindergarten students like 'something' to be repeated, they like to know what is coming, and also enables them to take part with greater confidence and enjoy the game. Therefore, it is a necessary part of a language lesson and as an element of competition that is something they enjoy and makes them stay interested. For that reason, an educational game can be as an alternative tool used in a classroom.

This study aims to describe the educational game "The Indonesian Tribes" as the multimedia application to facilitate the learning activities for the students in kindergarten. The design of this multimedia application is an educational game 
format and completed with the introduction and description of several tribes and cultures in Indonesia such as the traditional clothes, houses, dances in Indonesia, and the gamelan musical instruments. It is also completed with audio-visual animations in various contents, and interactive nature in terms of playing and learning activities with a simple description and instruction of the English language. This game is equipped with a Kinect sensor technology to detect the external trigger such as speech and gesture recognition that will further encourage the students to play while learning. It is in line with the characteristics of the kindergarten students who love to play and learn in their own imagination

\section{METHOD}

Arief Sadiman and his colleagues (2009) stated that they provided a sequence of steps to be taken in the development of media programs into six steps: analyze the needs and characteristics of students, formulate the operational and types of instructional objectives, formulate the particles of matter in detail that supports the achievement of goals, develop the tool measurements for success, write a script media, and conduct tests and revisions.

In this study, there were some phases in designing the educational game "Indonesia Tribes" as multimedia application. The first phase was conducting literature study and material specifications. There were some parts of the discussion that need to be prepared, which determine the field of introduction materials in term of interactive contents. The second phase was collecting the material in accordance with the basic needs and characteristics of the kindergarten students in learning process in order to get the appropriate teaching materials of these needs, and data processing. The subjects of materials then were developed into teaching materials. Then, conducting an analysis of the design of application development plan of teaching materials, in order to get a good response and can be applied as reference material or reference. The third phase was designing the learning materials through the game. The learning materials were designed in the form of educational game application development as well as the design. The fourth phase was developing the learning media through educational game.

\section{RESULTS AND DISCUSSIONS}

\section{Kinect sensor technology used in the educational game "Indonesia Tribes"}

Kinect sensor used in this game has 3 cameras. First is the left camera that sends laser projection. Then, the right camera which is infra-red (IR) which gets the distances of each joints at the resolution 320x240. The middle camera is a 30fps VGA camera at $640 \times 480$ resolutions. Kinect firmware has the function to calculate the skeleton structure by getting these data and sends the result to the PC. The system can measure distance with a 1 centimetre accuracy at 2 meters distance. Kinect also provides with three-dimensional data with the combination of image stream and depth stream. Furthermore, Kinect sensor has four microphones and a motor mechanism to adjust the Kinect tilt up and down. Communication of Kinect sensor with the application is illustrated in Figure 1. 


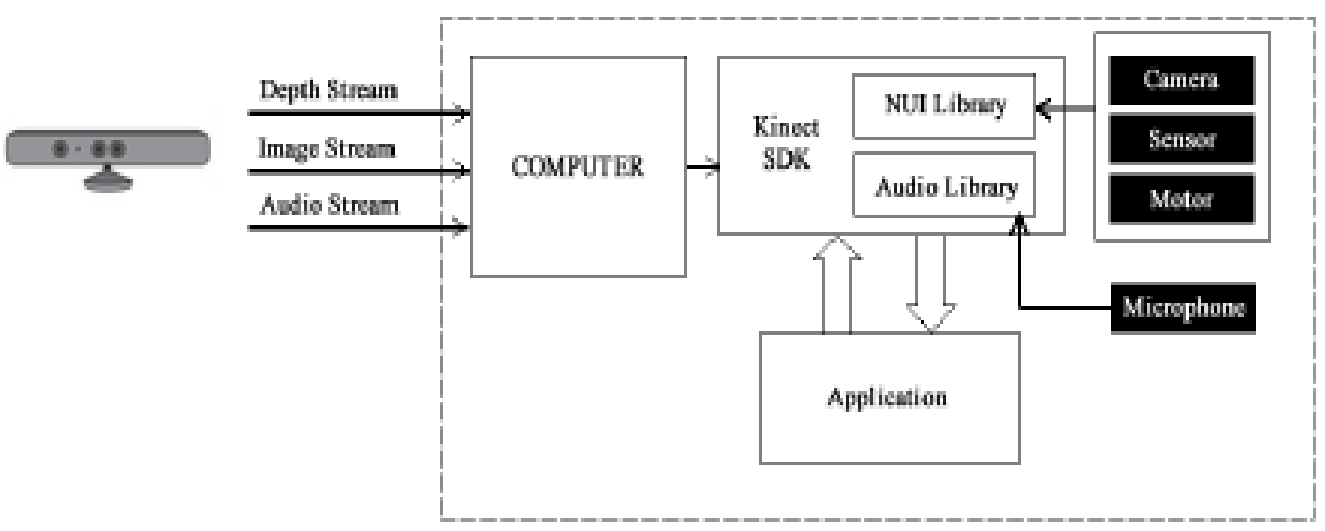

Fig. 1: Communication of Kinect Sensor with Application

The device features an "R=Red $\mathrm{G}=$ Green $\mathrm{B}=\mathrm{Blue}$ (RGB) camera, depth sensor and multi-array microphone running proprietary software", which provide full-body 3D motion capture, facial recognition and voice recognition capabilities. Kinect uses a sensor and a light source to capture RGB data and data depth. The leftmost part Kinect is a source of infrared light. The light-emitting diode (LED) indicator next to it is a marker of the sensor can communicate with a computer. The next longer exists RGB camera is used to capture RGB data while the far right is an infrared camera is used to capture the data depth. RGB cameras are able to support a resolution of 1280 x 960 while infrared camera supports a maximum resolution of $640 \times 480$ DI bottom there are 4 sensor microphone for speech recognition function.

\section{"The Indonesian Tribes" Game Design}

The educational game "The Indonesian Tribes" is designed with the interactive content by a script program and it can be played with many players. As the multimedia application, the capabilities of multimedia in presenting some interactive activities are gradually more complex and have rich contents. The application can display various texts, sounds, pictures, and audio-video. It also uses some sensors to detect the external setting or situation, the gesture recognition that can recognize the skeleton in human body, the speech recognition that can recognize the spoken words from players or users, and camera which can record the actual actions. Through the large quantity of features, this multimedia can be engineered as the learning tool in the form of educational game applications. Therefore, the use of this educational game can be varied, as just to fill the leisure-time (playing) until that is to learn while playing, and it makes the kindergarten students play while learning unconsciously. 


\section{The Design System of Learning Materials}

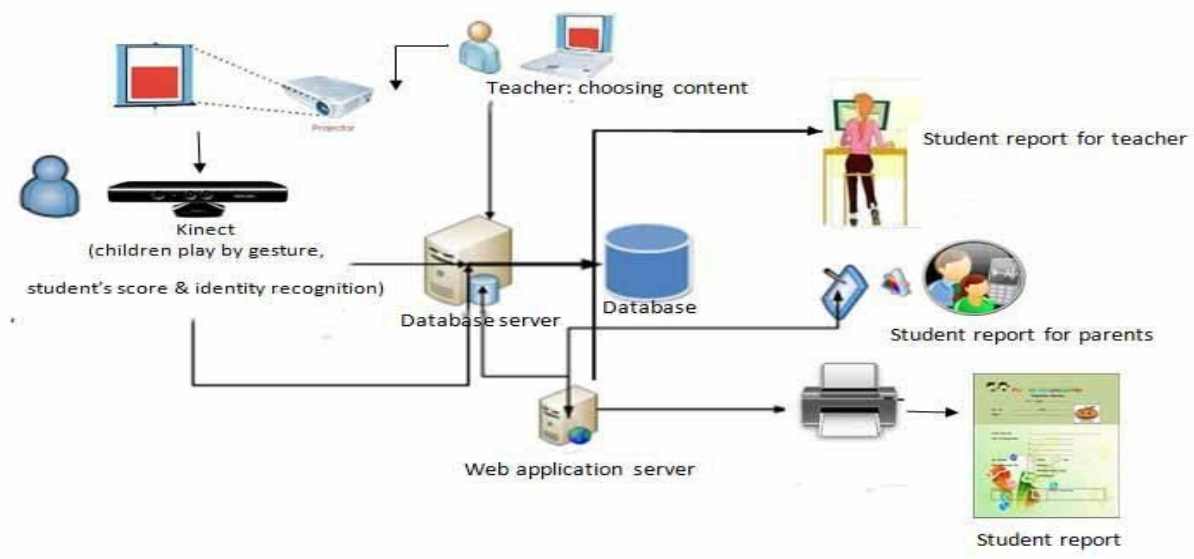

Fig. 2: The Design System Learning Materials (Siradj, et.al, 2014)

- The function of Kinect sensor is to capture the student's gesture based on the instruction that he/she should do in the game. The information gesture from the student will be processed in a media server and matched with the requirements of the game. If the gesture is appropriate with the requirements, the student will get point(s) and be recorded in his/her activities.

- Every student uses the identification form of quick reader (QR) code that affixed to his/her shoulders. Then, the webcam is positioned on the floor and faced on the ceiling. The captured data or information will be processed on the QR code and matched with the database. The matching process will determine automatically the name of the student who has played the game.

- This system also can be used to record the daily presence of the student. The data presence and activity of students during play the game will be collected by the web server and forwarded to their parents. Therefore, the parents can know what their children do and monitor their learning achievement progress every day.

- The media server also collects data for the monthly progress then made monthly reports and submitted online to the parents' smartphone.

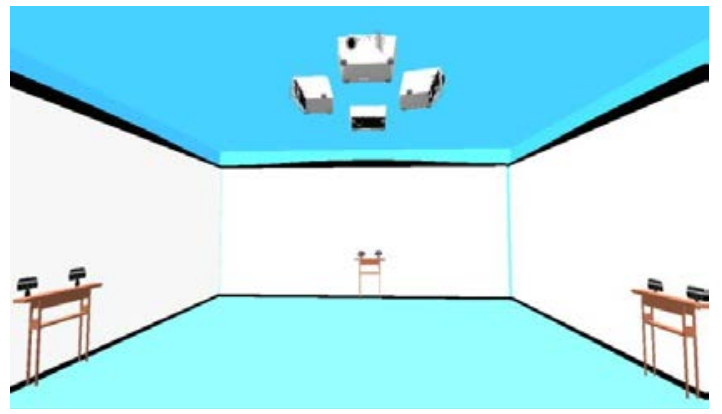

Fig. 3: The Implementation of Program (Siradj, et.al, 2014) 


\section{The Implementation of "the Indonesian Tribes" multimedia application}

In implementing the educational game "Indonesian Tribes", the room is designed with four full multimedia projectors that are facing on the wall with 4 Kinect sensors. The ideal size of room is $3 \times 3$ meters wide and can be possible used for 9 multi-players. There are some considerations that affect the quality of games on arrangement delivery as follows.

- Text Structur The resolution of the multimedia projector. With the higher resolution of the projector, the image which is appeared on the wall can be seen clearer and bigger.

- The lighting condition of the room. The directional of the light outdoor should be made in order not to compete with the light from the projector.

- The position of the projector and sound system. It is better to place the soundsystem tools and multimedia projector position on the ceiling to keep them away from the students.

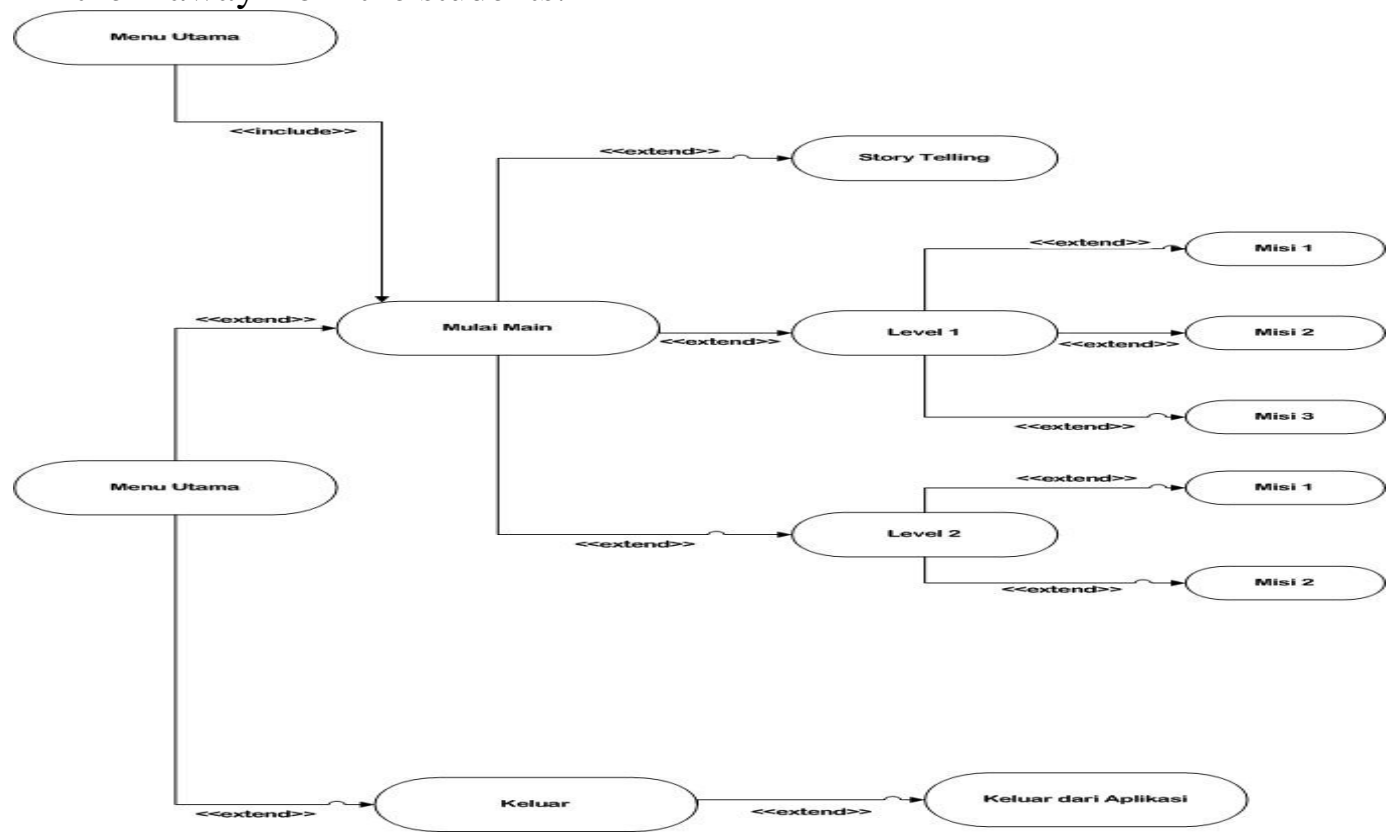

Fig. 4: The Diagram of Learning Activity (Siradj, et.al, 2014)

When the game starts, the webcam will capture the first sign of the presence of the student by QR code. When it has been identified, the student can start and select the game he/she likes or determined by the teacher. The game is also facilitated with the time arrangement in order to keep the student fresh and not too tired or bored. Before the game starts, there are several songs of the Indonesia tribes appeared on the lists. The more frequently they played; they can memorize the song well. The game is designed with the different level of difficulties, although it is not too significant to keep the motivation to play.

There are some choices on the game menu that can be selected by the students to start the game, such as; choose the position, view the content, choose the wall and view the temporary score. The process of selecting the position and choosing the wall game involves the webcam sensor assistance that determines the coordinates and brings the student at the centre of the wall where he/she plays the games. 


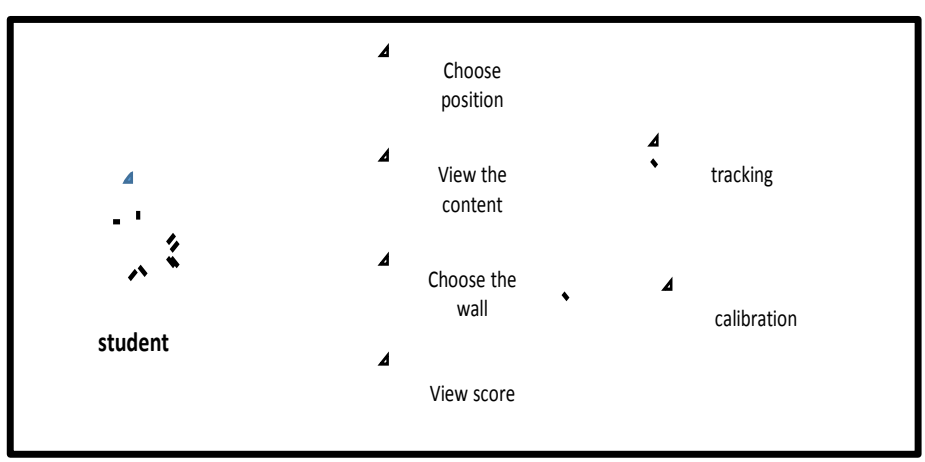

Fig. 5: Use Case Diagram for Student(s)

For teachers, the use of the educational game "Indonesia Tribes" can increase the teaching creativity and create a good atmosphere of learning. The use case diagram for teachers on figure 6 explains that there are some functions that are built; input data of student, check the presence list of student, choose the content, view the position of the students, and print reports.

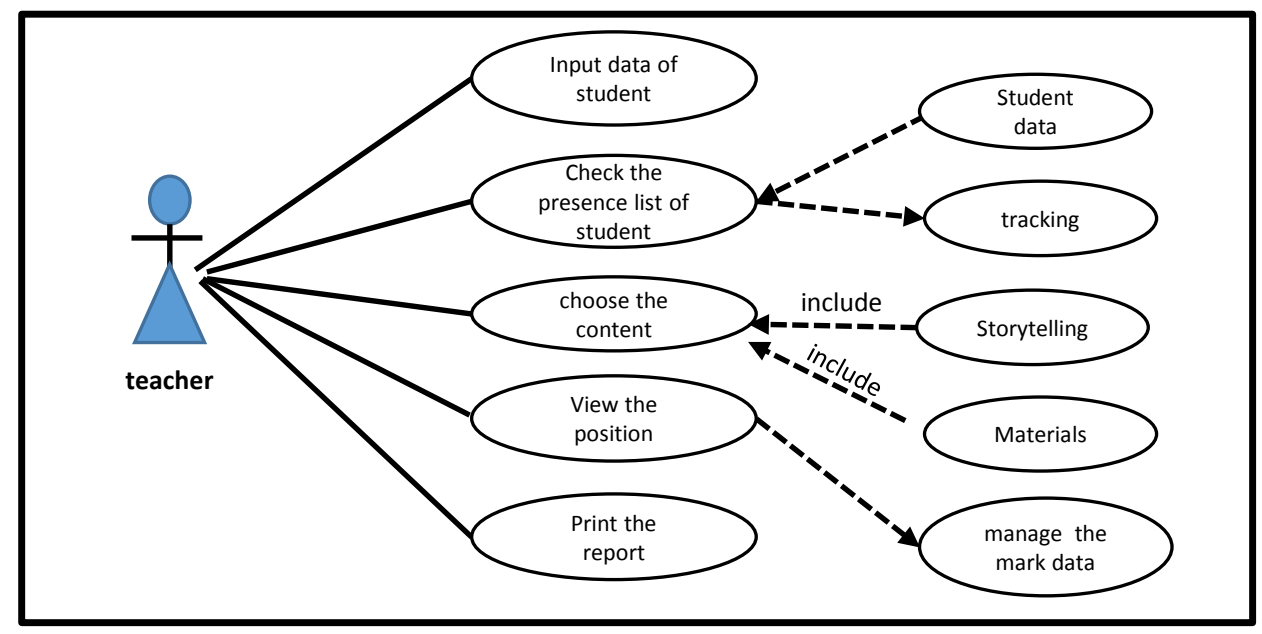

Regular Papers should be prepared with the headings Introduction, Materials and Methods, Results and Discussion, Conclusions, Acknowledgements, References, and Supplementary data (if available) in this order.

\section{The Educational Game “Indonesian Tribes” Interfaces}

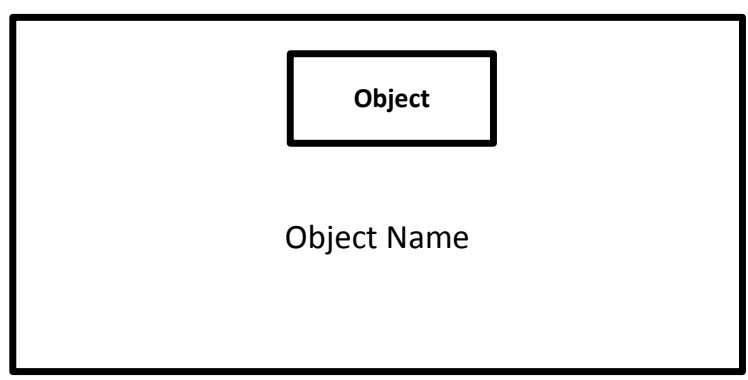

Fig. 7: The Storyboard of Main Menu

On the main menu, the student can choose his/her favourite game to play by using the hand gestures, the student then moves beyond the mouse button (hover) and paused until the action button depressed. The next scene that appears will be depending on the selected button. 


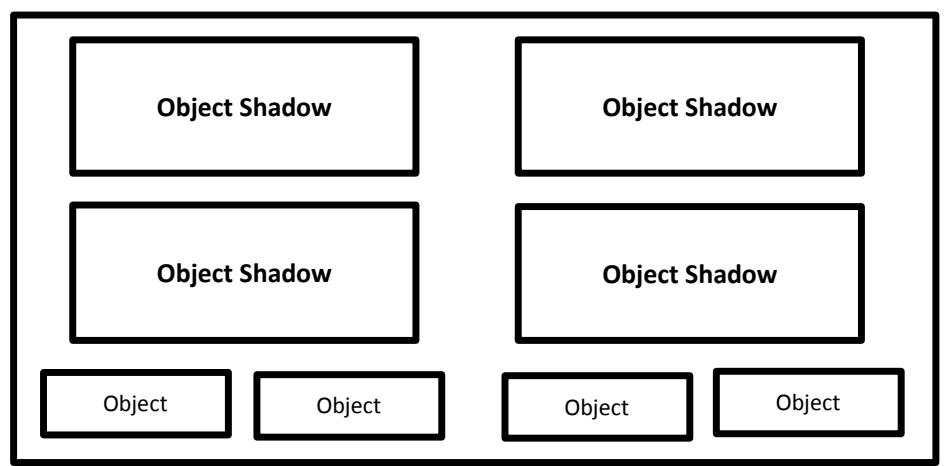

Fig. 8: The Storyboard of Game Scene

The storyboard of game scene illustrates the position of the object and the shadow of the matching object. In picture 1, there are several objects shadow and those are placed randomly. The students should "drag" to match the object position. Every image that mates with shadow will add points or marks to the students.

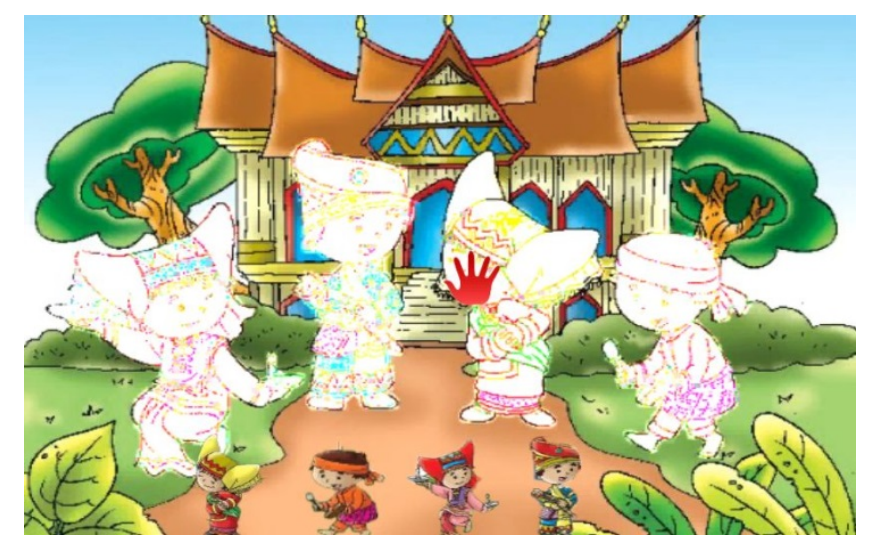

Pic. 1: "The Indonesian Tribes” Game Scene - Traditional Clothes

In a linear sequence, the game starts with the introduction of ethnic groups in Indonesia completed with the explanation of how to play. For example the game 1 that ask the students to match the traditional clothes with the silhouette. The student must move the hand cursor toward the below picture and "drag" it to the corresponding shadow.
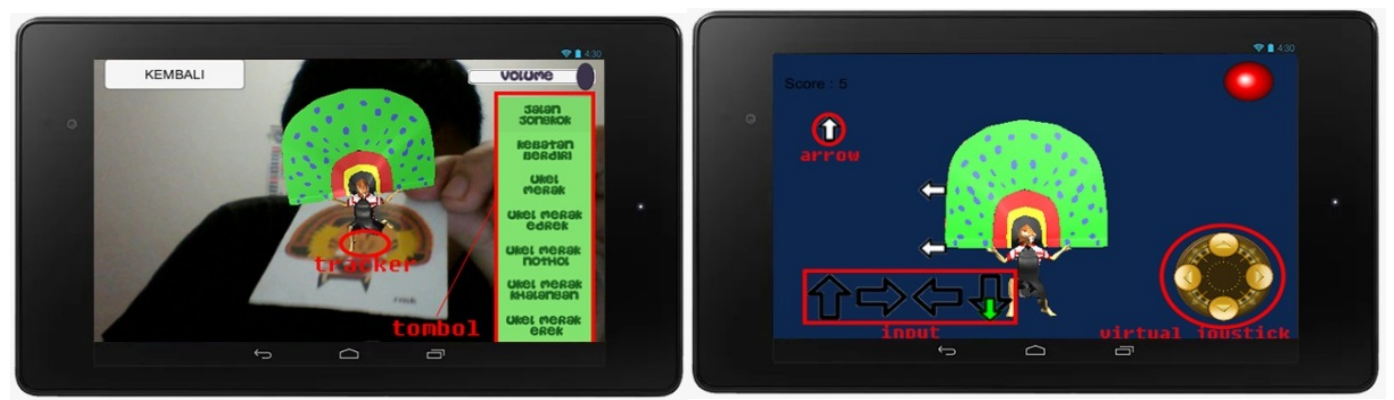

Pic. 2: “The Indonesian Tribes” Game Scene - Traditional Dances

The implementation of a game that has been embellished artistically that can be applied in the smartphone with android basis as illustrated on picture 2 . The scene 
is made as complete as possible in accordance with the national custom databases that exist in Indonesia.

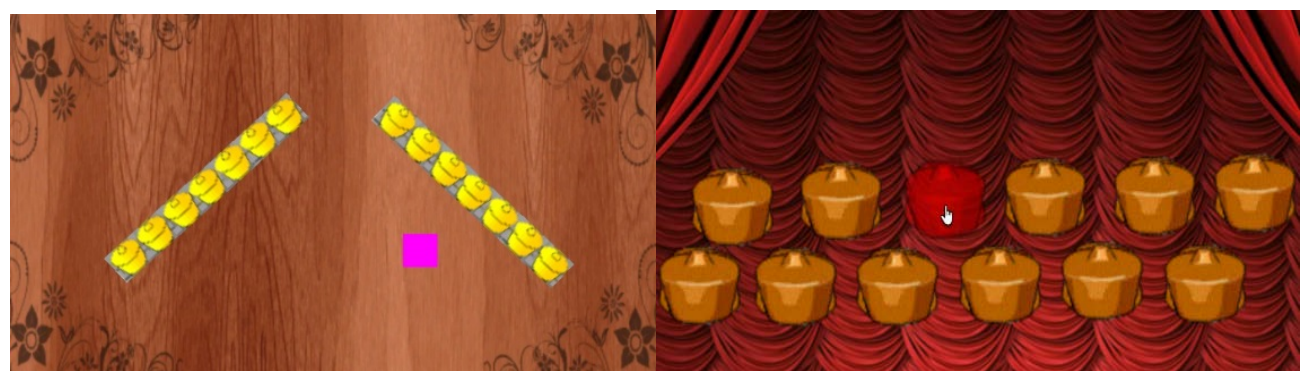

Pic. 3: “The Indonesian Tribes” Game Scene - Gamelan Instruments

The introduction of gamelan game is also completed with the instruction on how to play the music instruments. In the introduction to gamelan game, students will be treated in advance about the history of the 'orchestra' and how to play. In playing the gamelan music instruments, the students can play together with the teacher or their classmates.

All the games are completed with audio-visual animations in various contents, and interactive nature in terms of playing and learning activities with a simple description and instruction of the English language. Therefore, the implementation of interactive contents in this application enable them to have some senses owned better and more effective, such as the senses of sight, hearing, and motoric functions.

\section{CONCLUSION}

The educational game "The Indonesian Tribes" is a multimedia application that is designed to facilitate the kindergarten students. There are some games of Indonesia tribes and cultures in this application such as the traditional clothes, houses, dances, and the gamelan musical instruments. This application is equipped with a Kinect sensor technology to detect the external trigger such as speech and gesture recognition that will encourage the liveliness children play while learning. It is in line with the characteristics of the kindergarten students who love to play and learn in their own imagination. The game is also completed with audio-visual animations in various contents, and interactive nature in terms of playing and learning activities with a simple description and instruction of the English language. The implementation of interactive contents in this application enable them to have some senses owned better and more effective, such as the senses of sight, hearing, and motorist functions. Also for teachers, it can increase the teaching creativity and create a good atmosphere of learning.

\section{ACKNOWLEDGEMENTS}

The authors would like to thank for Director of Research and Community Service of the Directorate General of Strengthening Research and Development from the Ministry of Research, Technology and Higher Education of the Republic of 
Indonesia, for providing the research grant of "Hibah Bersaing", so that this study could be well accomplished.

\section{REFERENCES}

Adams, D.M. (1973). Simulation Games: An Approach to learning. Worthington, OH: C.A. Jones.

Aldrich, H.E., Ruef, M. (2006). Organizations Evolving. London: Sage Publications: 16-60. Accessed at: http://fhs-bio-wiki.pbworks.com/w/page/24126934/What\%20is\%20Evolution on October $2^{\text {nd }}$, 2014.

Anggani Sudono (1988). Sumber Belajar dan Alat Permainan Untuk Pendidikan Usia Dini. Jakarta. Grasindo.

Arief S. Sadiman., Rahardjo, R., Haryono, Anung., Rahardjito. (2009). Media Pendidikan, Pengertian, Pengembangan, dan Pemanfaatannya. Jakarta: Rajawali Press.

Arikunto Su Harsimi (1992). Pengelolaan Kelas dan Siswa Sebuah Pendekatan Evaluatif. Jakarta; Rajawali.

Carrol Ja. (1991). Centers for Early Learners Throughout the Year. Chartage, Good Apple.

Demes da Cruz, G. (2008). English Teaching Professional. Let Us Play, 58, 18.

Depdiknas. (2004). Kurikulum 2004 Standar Kompetensi Taman Kanak-kanak dan Roudlotul Athfal. Jakarta : Departemen Pendidikan Nasional.

Harmer, Jerremy. (2001). The Practice of English Language Teaching $3^{\text {rd }}$ Edition. New York: Longman, Inc.

Juwita. D. (2010). Perkembangan Fisik Motorik dan Bahasa. Surakarta: Universitas Muhammadiyah Surakarta.

Marsh, Jackie., Brooks, Greg., Hughes, Jane., Ritchie, Louise., Roberts, Samuel. \& Wright, Katy (2005). Digital Beginnings: Young Children's Use of Popular Culture, Media and New Technologies. Sheffield: University of Sheffied. Accessed from: http://www.digitalbeginings.shef.ac.uk/ on October 2 $2^{\text {nd }}, 2014$.

Microsoft. (2012). "Kinect for Windows SDK 1.6 Programming Guide". Microsoft. Retrieved February 16, 2015.

Prensky, Marc. (2001). "Fun, Play and Games: What Makes Games Engaging." Digital GameBased Learning. McGraw-Hill. Accessed at http://www.marcprensky.com/writing/Prensky\%20-\%20Digital\%20GameBased\%20Learning-Ch5.pdf on July 30 ${ }^{\text {th }}, 2016$.

Siradj, Yahdi, et.all. (2014). Designing and Implementing Knowing Indonesian Tribes Game in Future Kindergarten. Bandung: School of Electrical Engineering and Informatics, Bandung Institute of Technology.

Wijayanto, P. W., and Siradj, Y. (2015). "Designing the Educational Game "The Indonesian Tribes” for Kindergarten Students”. National Proceeding. The $3^{\text {trd }}$ Asia-Pacific Education Conference (The 3rd AECon). University of Muhammadiyah Purwokerto: 49-59.

Wijayanto, P. W., and Siradj, Y. (2016). Designing and Implementing the Educational Game "Indonesian Tribes" for the Kindergarten Students. Vision Journal: Journal for Language and Foreign Language Learning. Volume 5, No 2 (2016). Accessed at http://journal.walisongo.ac.id/index.php/vision/issue/view/161 on October $10^{\text {th }}, 2016$. 